\title{
Knowledge and practices of nurses regarding nosocomial infection control measures in private hospitals in Sana'a City, Yemen
}

\author{
Gamil Alrubaiee ${ }^{1 *}$, Anisah Baharom ${ }^{1}$, Hayati Kadir Shahar ${ }^{1}$, Shaffe Mohd Daud ${ }^{2}$ and Huda Omar Basaleem ${ }^{3}$
}

\begin{abstract}
Background: In the Yemeni healthcare setting, basic infection control measures are necessary to reduce the rates of hospital-associated infections.

Methods: A descriptive cross-sectional study was conducted from April to May 2016. A non-probability sample of 100 nurses working in the private hospitals located in the capital city of Yemen was selected as study participants. A 45-item questionnaire was used to assess knowledge and practices regarding nosocomial infection control measures among the study subjects. The collected data were analyzed by SPSS (version 22.0).

Results: The highest percentage of nurses were males (61.2\%) and aging between 25 and above (71.8\%) and had 3 years nursing diploma (60\%), less than 5 years of employment in the hospitals (56.5\%), relatively high training course about nosocomial infections (NIs) (64.7\%), and working experience in infection control (78.8\%). Most of the nurses (87\%) had a fair level of knowledge, while only $4 \%$ of them had a good level of knowledge of preventive measures of nosocomial infections. The results also revealed that the majority of the nurses (71\%) had fair practices about nosocomial infections whereas $26 \%$ of them had good practices and only $3 \%$ of them had poor practices.

Conclusion: The gaps in knowledge and practices regarding $\mathrm{NI}$ control measures indicate the need to establish a related health care policy regarding NIs and implement a regular training program to upgrade and refresh the nurses' knowledge and practices regarding $\mathrm{NI}$ control measures.
\end{abstract}

Keywords: Nosocomial infections, Hospital-acquired infections, Hospital-associated infections, Cross infection, Yemen

\section{Background}

Nosocomial infections (NIs), also known as a hospitalacquired infection, are defined as infections which are acquired after $48 \mathrm{~h}$ of patient admission. Such infections are neither present nor incubating prior to a patient's admission to a given hospital. NIs represent a universally serious health problem and a major concern for the safety of both patients and the health care providers [1-4]. Although the incidence rate for nosocomial infection vary from country to country, at any given time, almost seven patients from developed countries to ten

\footnotetext{
*Correspondence: alrubaiee73@gmail.com

'Department of Community Health, Faculty of Medicine and Health Sciences, Universiti Putra Malaysia, Serdang, Malaysia

Full list of author information is available at the end of the article
}

patients from developing countries out of each100 patients admitted to hospitals gain at least one kind of nosocomial infections [5]. In Yemen, data regarding NIs are few, but the prevalence rate of NIs, specifically surgical site infection, is high from time to time as it accounted for $8 \%$ in 2002 [6] and 34\% in 2013 [7].

NIs have significant consequences on patients, their families, and the community as a whole. The most common consequences of NIs are increased morbidity, mortality, and length of hospitalization $[4,8]$. Such consequences contribute substantially to raise both the direct and indirect cost of the health care services, which result in additional costs to treat infected cases. Hence, such issue wastes the available resources which are not already enough, especially in developing countries [9]. 
Nurses are responsible for providing medications, dressing, sterilization, and disinfection. They are involved in more contact with patients than other health care workers (HCWs). Therefore, they are more exposed to various NIs [10]. Hence, nurses play a vital role in transmitting NIs, and their compliance with infection control measures seems to be necessary for preventing and controlling NIs [11]. Accordingly, they should be aware of how to prevent transmission of NIs and be knowledgeable of its potential risk to patients, other staff, and as visitors.

Although there are many previous cross-sectional studies which revealed that the levels of nurses' knowledge and practices are relatively poor and insufficient [12-15], to the researcher's best of knowledge, so far, no study has been conducted in Yemen which is the context of the current study. Therefore, this study aimed to identify gaps in nurses' knowledge and practices regarding NI control measures in order to improve the current training courses and enhance future good practice.

\section{Methods}

Aim

This study aims to answer the following research questions:

1. What is the current level of knowledge of nurses regarding infection control measures?

2. What is the current level of practices of nurses regarding infection control measures?

\section{Study design}

A descriptive, cross-sectional design was used in this study.

\section{Study setting}

This study was carried out in two private hospitals in Sana'a, the capital city of Yemen. The study covered a period from April 2016 to May 2016. All nurses who were working in the selected private hospitals and involved in a direct contact with patients were invited to participate in this study.

\section{Subjects}

A non-probability (purposive) sampling technique was used to select the study participants. A total of 100 nurses participated in this study and responded to the study questionnaire. However, only 85 questionnaires were filled completely and included in the final analysis.

\section{Study instrument}

A structured questionnaire was developed based on the World Health Organization (WHO) infection control guidelines [9]. The final questionnaire comprised 45 items related to knowledge and practice regarding NI control measures. It is divided into the following three sections:

Section 1 is related to the demographic information of the participants: age, gender, level of education, current position and duration of working, course training on NI control, and working experience in NI control measures.

Section 2 is related to knowledge and is divided into these two parts:

1. Knowledge of preventive measures of person-to-person transmission, which includes hand hygiene (5 items), personal protective equipment ( 5 items), and safe injection practices (4 items)

2. Knowledge of preventive measures of transmission from hospital environment, which involves routine hospital cleaning (4 items), safe waste handling and disposal (4 items), reprocessing of patient care equipment (4 items), and safe linen handling (4 items)

Section 3 is related to practices on NI control measures, and it consists of 15 items. This section is also subdivided into two parts: precautions to prevent NIs ( 9 items) and actual actions to prevent NIs (6 items).

\section{Scoring system}

The 30 items related to knowledge were assessed with "Correct," "Incorrect," and "I don't know" options, while the practices was assessed using 15 scenario-based items with "Yes," "No," and "I don't know" options. The reverse statement was corrected first and then a 0 score was given for each "incorrect" or "I don't know" response; 1 score was given for each correct response. The maximum and minimum scores for each section vary based on the number of items in each section. Correct answers were calculated to obtain total scores for different infection control practices. A score of less than $50 \%$ was considered poor, $50-79 \%$ fair, and $80 \%$ and above was considered as good [16].

\section{Validity and reliability}

Content validity was obtained by three experts in infection control and prevention at hospitals and academic institutions. Their comments regarding the tool layout and format, relevance, accuracy, consistency, and scoring system were taken in consideration. Reliability of the tool items was tested using alpha Cronbach $(\alpha)$ test: section 2 of the tool $=0.81$ and section $3=0.79$ which considered acceptable.

The responses were recorded and analyzed using the statistical software (IBMSPSS), version 22.0. Descriptive statistics was applied (percent and number). A $p$ value of $\leq 0.05$ was taken as statistically significant. 


\section{Data collection}

The questionnaire was distributed during the study period of April to May 2016. In-ward nurses from both hospitals were invited during regularly scheduled educational meetings to fill the questionnaire and had to return it back at the same time to avoid any non-response bias. A total of 100 questionnaire were distributed, 50 in each hospital. Only 85 out of the 100 distributed questionnaires were completed, and therefore, they were used in the final analysis.

\section{Ethics}

Permission for this study was obtained from the Ethics Committee of both selected private hospitals (University of Science and Technology and Saudi German Hospital Sana'a). A written consent was also obtained from all eligible nurses before data collection.

\section{Results}

\section{Response rate}

Out of 100 distributed questionnaires, 85 questionnaires were filled completely and included in the final analysis, thus making up a response rate of $85 \%$.

\section{Demographic details of the respondents}

The results of the study showed that the majority of the nurses $(61.2 \%)$ were males and they were the age group of 25 years and above (71.8\%). Sixty percent of them had a 3-year diploma and $95.3 \%$ were staff nurse. Regarding duration of work, $56.5 \%$ of the participating nurses had less than 5 years of working experience. Around two thirds of the nurses (64.7\%) had attended training courses, whereas $78.8 \%$ of them had working experience in infection control. Further details of the respondents' demographic characteristics are presented in Table 1.

\section{Nurses' knowledge on person-to-person infection control measures}

The results of the study showed that the majority (72.9\%) of the Yemeni nurses had a fair level of knowledge on hand hygiene, while almost above of the third (35.3\%) had a good level of knowledge on PPE. Likewise, more than half of the nurses $(67.1 \%)$ had a poor level of knowledge regarding safe injection practices. Further details are given in Table 2.

\section{Nurses' knowledge on preventive measures of transmission from hospital environment}

Regarding the preventive measures used in preventing transmission of infections from the hospital environment, the results revealed that more than half (52.9\%) of the participants had a good level of knowledge on routine hospital cleaning and the majority $(81.1 \%)$ of them had a fair level of knowledge on safe waste handling and
Table 1 The distribution of the respondents according to demographic characteristics $(N=85)$

\begin{tabular}{ll}
\hline Demographic details & Total $n(\%)$ \\
\hline Age (in years) & $24(28.2)$ \\
$<25$ & $61(71.8)$ \\
$25+$ & \\
Gender & $52(61.2)$ \\
Male & $33(38.8)$ \\
Female & \\
Level of education & $51(60.0)$ \\
Diploma degree & $34(40.0)$ \\
Bachelor degree & \\
Current position & $81(95.3)$ \\
Staff nurse & $4(4.7)$ \\
Head nurse & \\
Duration of working experience & $48(56.5)$ \\
$\leq 5$ years & $37(43.5)$ \\
$>5$ years & \\
Course training on infection control & \\
Yes & $55(64.7)$ \\
No & $30(35.3)$ \\
Working experience in infection control & \\
Yes & $67(78.8)$ \\
No & $181.2)$ \\
\hline
\end{tabular}

disposal. It was also found that more than two thirds $(82.8 \%)$ of the nurses had a fair level of knowledge on patient care equipment reprocessing, while above half (60\%) of them had a poor level of knowledge of safe linen handling. More details are given in Table 3.

\section{Overall level of knowledge on different NI control measures}

The results of the current study showed that the majority $(87 \%)$ of the participants had a fair level of knowledge on the different NI preventive measures. However, $9 \%$ of them had a poor level of knowledge, and only $4 \%$ of them had a good level of knowledge on the different NI preventive measures. The results are illustrated in Fig. 1.

Table 2 Nurses' knowledge on different preventive measures of person-to-person infection transmission $(N=85)$

\begin{tabular}{llll}
\hline Different practices & \multicolumn{2}{l}{ Level of knowledge } \\
\cline { 2 - 4 } & $\begin{array}{l}\text { Poor } \\
(>50 \% \text { score })\end{array}$ & $\begin{array}{l}\text { Fair } \\
(50-79 \% \text { score })\end{array}$ & $\begin{array}{l}\text { Good } \\
\text { ( } 580 \% \text { score })\end{array}$ \\
\hline Hand hygiene & $14(16.5)$ & $62(72.9)$ & $9(10.6)$ \\
Personal protective & $32(37.6)$ & $23(27.1)$ & $31(35.3)$ \\
equipment & & & \\
Safe injection practices & $57(67.1)$ & $28(32.9)$ & $0(0.0)$ \\
\hline
\end{tabular}


Table 3 Nurses' knowledge on preventive measures of transmission from hospital environment $(N=85)$

\begin{tabular}{|c|c|c|c|}
\hline \multirow[t]{2}{*}{ Different practices } & \multicolumn{3}{|l|}{ Level of knowledge } \\
\hline & Poor (> 50\% score) & Fair (50-79\% score) & Good ( $\leq 80 \%$ score) \\
\hline Routine hospital cleaning & $4(4.7)$ & $36(42.4)$ & $45(52.9)$ \\
\hline Safe waste handling and disposal & $7(8.2)$ & $69(81.1)$ & $9(10.6)$ \\
\hline Patient care equipment reprocessing & $2(2.4)$ & $70(82.8)$ & $13(15.3)$ \\
\hline Safe linen handling & $51(60)$ & $33(38.8)$ & $1(1.2)$ \\
\hline
\end{tabular}

Level of nurses' practices of different NI control measures Based on the findings of the study in Table 4, most of the nurses $(74.1 \%)$ had good practices on actual actions utilized to prevent NIs, while $71.8 \%$ of them reported fair practices regarding precautions to prevent NIs. Further details are presented in Table 4.

Overall level of practices on different $\mathrm{NI}$ control measures Figure 2 indicates that the majority (71\%) of nurses had fair overall practices, whereas $26 \%$ of them demonstrated good practices on different infection prevention and control measures.

\section{Discussion}

NIs increase patients' morbidity, mortality, the length of hospital stay, and treatment cost (Ginny [17]). Therefore, infection prevention and control are important to prevent the occurrence of NIs in health and hospital settings. During patients' nursing care, it is thus of utmost importance for nurses to have the knowledge and appropriate practice of infection prevention and control measures. This study aimed to determine the level of nurses' knowledge and practices regarding NIs.

Based on the results of the present study, the majority of the Yemeni participating nurses were 25 years old and above (71.8\%). This result is similar to the result reported in previous studies conducted by Ginny Kaushal et al. [17] in India, Johnson et al. [18] in Nigeria,

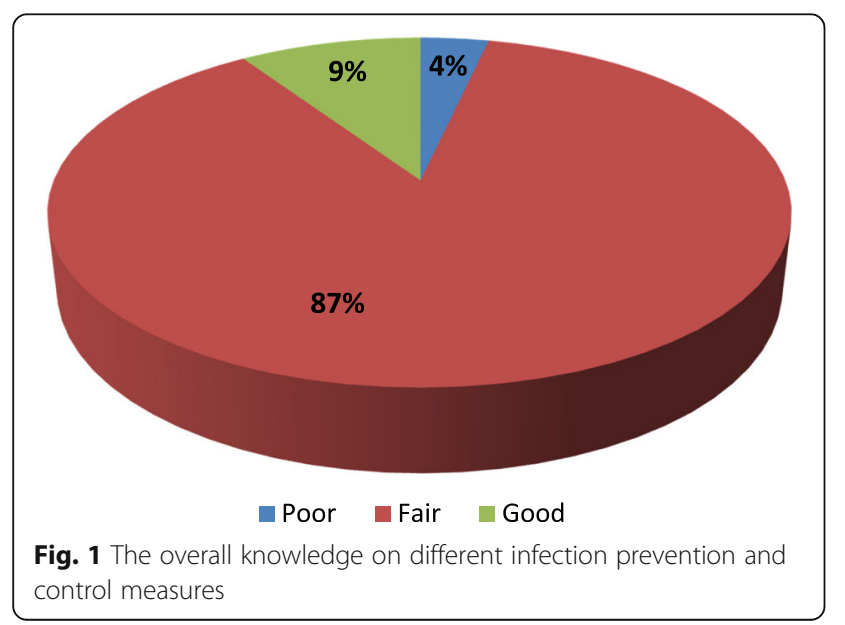

and Reda et al. [19] in Ethiopia. Furthermore, the results revealed that almost above half $(61.2 \%)$ of the participants were male holding nursing diploma (60\%), which corroborates what was reported by El-Sayed et al. [20] in regard to nursing diploma. However, our result is inconsistent with this previous study concerning the gender as El-Sayed et al. [20] reported that most of the study participants were females. Thus, why the males outnumbered the females in the current study could be explained from a cultural and religious perspective. In other words, in many Middle East countries, cultural and Islamic perspectives still prevent female nurses from working in the night shift or working in the male's wards. Regarding years of employment in the hospital, about half of nurses (56.5\%) were found to have less than 5 years of experience. This result is compatible with the result obtained by Fashafsheh et al. [16] who found that about $(43.9 \%)$ of the participants had working experience of 5 years or less. Such result indicates that new employees seem to be more cooperative than senior ones to participate in research. The current study also revealed that most of the participants (64.7\%) attended annual continuing education courses about infection control. This result is compatible with Ebied [21] who found that more than half of nurses attended infection control course and continuing education programs. In contrast, such result is inconsistent with the result reported by Fashafsheh et al. [16] who indicated that most $(63.8 \%)$ of the nurses had no training course about NIs. This contrast in results could be due to the difference in setting and targeted group from study to another study. The difference in in-service training-related policy could also be another factor for this difference.

Regarding the level of nurses' knowledge on different preventive measures of person-to-person infection transmission, our study showed that the majority $(72.9 \%)$ of

Table 4 Nurses' practices on $\mathrm{Nl}$ control measures $(N=85)$

\begin{tabular}{llll}
\hline Different practices & \multicolumn{2}{l}{ Level of practices } & \\
\cline { 2 - 4 } & $\begin{array}{l}\text { Poor } \\
\text { (> 50\% score) }\end{array}$ & $\begin{array}{l}\text { Fair } \\
(50-79 \% \text { score })\end{array}$ & $\begin{array}{l}\text { Good } \\
\text { ( } 580 \% \text { score })\end{array}$ \\
\hline $\begin{array}{l}\text { Precautions to prevent } \\
\text { Nls }\end{array}$ & $4(4.7)$ & $61(71.8)$ & $20(23.5)$ \\
Actual actions to prevent & $2(2.4)$ & $20(23.5)$ & $63(74.1)$ \\
Nls & & & \\
\hline
\end{tabular}




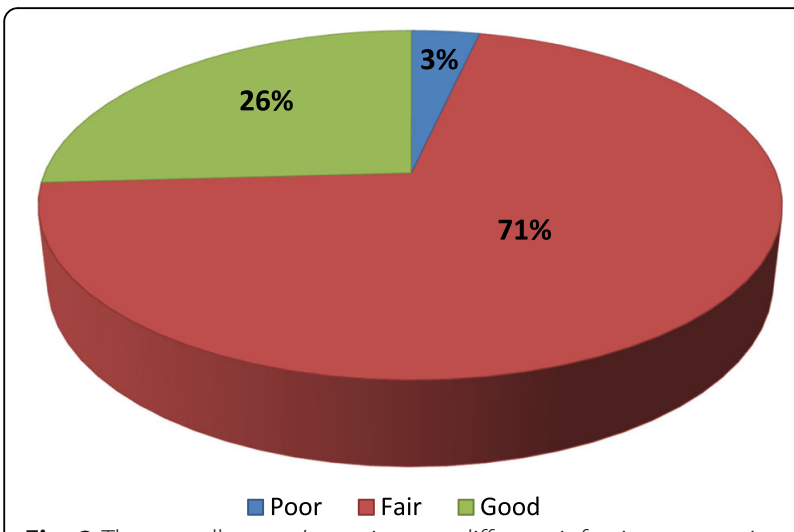

Fig. 2 The overall nurses' practices on different infection prevention and control measures

the participants had a fair level of knowledge of Hand hygiene. Almost two thirds of the participants were found to have fair (27.1\%) and good (35.3\%) levels of knowledge on personal protective equipment. The results also demonstrated that there were above half (67.1\%) of the participants which had a poor level of knowledge and $32.9 \%$ of them had a fair level of knowledge; none of the participants had good knowledge on safe injection practices. For the nurses' knowledge on different preventive measures of transmission from hospital environment, it was found that above half (52.9\%) of the participants had a good level of knowledge of routine hospital cleaning and the majority (81.1 and 82.8\%) had a fair level of knowledge on safe waste handling and disposal and patient care equipment reprocessing, respectively. However, above half of the Yemeni nurses (60\%) had a poor level of knowledge of safe linen handling. In general, regarding the overall nurses' knowledge on the different infection prevention and control measures, it was found to be fair (87\%). It was even higher than what was found by Abdulraheem et al. [12] in Northern Nigeria and Shamaa and Talaat [15] in Egypt and Isara and Ofili [22] in the Federal Medical center. The knowledge level in these studies was $(12.9,10$, and $37.7 \%)$, respectively. However, the level of knowledge in the current study is lower than what was found by Vaz et al. [23] and Labrague et al. [24], as it accounted for 90 and $89.7 \%$, respectively. Such different levels of knowledge among nurses in these different studies might be due to the inadequacy of infection prevention and control training' education, as it was found that those nurses who attended in-service training courses achieved a high knowledge scores [25]. In particular, the results highlighted the necessity to implement an in-service training course on infection control measures with more focusing on safe injection practices and safe linen handling because nurses had had poor knowledge in these two aspects.
Concerning the level of nurses' practices regarding infection prevention and control measures, the present study indicates that the majority $(71.8 \%)$ of the Yemeni nurses had a fair level of practices in regard with precautions to prevent NIs, while nearly a third of them had a good level of practices on these precautions. However, the study demonstrates that almost two thirds (74.1) of the nurses had a good level of practices on actual actions to prevent NIs. In general, the study revealed that the majority (71\%) of the participants had a fair overall level of practices, whereas $26 \%$ of them had good overall practices regarding different NI prevention and control. This result is close to the result by Eskander et al. [25] which showed that the level of practice was more than $75 \%$. However, it is less than what was obtained by Fashafsheh et al. [16] as it was $91.14 \%$, but it is higher than what was found in many other studies [18, 20, 26, 27] as this level of practice accounted for 20, 48.7, 55.3, and $57.5 \%$, respectively. This discrepancy in results could be due to the difference in participants' attitudes towards utilizing infection control measure methods. It could also be either due to the difference in the operational definition of the good practice from one study to another study or due to the difference in knowledge of the nurses regarding infection prevention and control. Furthermore, although the nurses showed a fair level of practices about the precautions that should be used to prevent NIs, they demonstrated a good level of practices in the actual actions as a way to prevent NIs during the daily activities. This could be an indication of the existing contrast between theory and practice, which reflects the need for linking theoretical to practical aspects in curriculum addressing infection control measures.

\section{Limitations}

Our study has several limitations, which should be addressed for future research. The study was exclusive to private hospitals and nurses, and it used purposive sampling method. Therefore, generalizability of the results needs to be taken with caution. The selection bias also might exist in this study. Furthermore, our study determined the self-reported practices, but how nurses are translating these practices in the real clinical practices needs further investigation.

\section{Conclusion}

Based on the findings of this study, it could be concluded that the majority of the Yemeni nurses had fair knowledge and practices regarding NI control measures. Therefore, future research should focus on improving knowledge and practices among nurses through educational intervention, during either their training courses or in-service refresher courses by assessing their knowledge and practices before and after intervention. 
Further studies involving both public and private hospitals are also recommended.

\section{Abbreviations}

IBMSPSS: Statistical Package for the Social Sciences; NIs: Nosocomial infections; WHO: World Health Organization

\section{Acknowledgements}

We would like to thank all the nurses who willingly agreed to participate in this study as well as to those who helped us in the data collection, particularly the head of nursing departments in the selected hospitals. Also, we wish to thank the managers of the private hospitals for their agreement, cooperation, and assistance.

\section{Funding}

This study has not received any types of grants to support

\section{Availability of data and materials}

As stated in the respondents' consent, the data used in the current study is confidential and cannot be publicly shared but is available from the corresponding author on a reasonable request.

\section{Authors' contributions}

GGA, AB, HKS, SMD, and $\mathrm{HOB}$ were involved in the notion and the study design. GGA was responsible for the data collection and analysis. All the authors contributed in the data interpretation, reviewing and drafting the manuscript, and approved the final manuscript.

\section{Ethics approval and consent to participate}

Ethical approval was obtained from the Ethics Committee of University of Science and Technology hospital and Saudi German Hospital Sana'a, where data were collected. Written consent using respondents' sheet and consent was also obtained from all eligible participants prior to conducting this study.

\section{Consent for publication}

Not applicable

\section{Competing interests}

The authors declare that they have no competing interests.

\section{Publisher's Note}

Springer Nature remains neutral with regard to jurisdictional claims in published maps and institutional affiliations.

\section{Author details}

${ }^{1}$ Department of Community Health, Faculty of Medicine and Health Sciences, Universiti Putra Malaysia, Serdang, Malaysia. ${ }^{2}$ Department of Foundations of Education, Faculty of Educational Studies, Universiti Putra Malaysia, Serdang, Malaysia. ${ }^{3}$ Department of Community Medicine and Public Health, Faculty of Medicine and Health Sciences, University of Aden, Aden, Yemen.

\section{Received: 18 October 2017 Accepted: 28 November 2017}

Published online: 15 December 2017

\section{References}

1. Iliyasu G, Dayyab FM, Habib ZG, Tiamiyu AB, Abubakar S, Mijinyawa MS, et al. Knowledge and practices of infection control among healthcare workers in a tertiary referral center in North-Western Nigeria. Ann Afr Med. 2016;15(1):34

2. Kamunge EW. Exploring knowledge, attitudes and practices of registered nurses regarding the spread of nosocomial infections, in health and medical sciences. 2013, Seton Hall University Dissertations and Theses (ETDs). New Jersey; 1865

3. WHO. WHO guidelines on hand hygiene in health care. Geneva: WHO; 2010 ISBN, 978(92), 4

4. Allegranzi $B$, et al. Report on the burden of endemic health care-associated infection worldwide. Geneva: World Health Organization; 2011.

5. WHO Health care-associated infections fact sheet. World Health Organization; 2014.
6. Raja'a YA, Salam AR, Salih YA, Salman MS, Al-Baseer LS, Al-Kirshi NA, et al. Rate and risk factors of surgical site infections with antibiotic prophylaxis. Saudi Med J. 2002;23(6):672-4.

7. Nasser AM, Zhang X, Yang L, Sawafta FJ, Salah B. Assessment of surgical site infections from signs \& symptoms of the wound and associated factors in public hospitals of Hodeidah City, Yemen. Int J Appl. 2013;3(3):101-10.

8. Samuel S, Kayode O, Musa O, Nwigwe G, Aboderin A, Salami T, et al. Nosocomial infections and the challenges of control in developing countries. Afr J Clin Exp Microbiol. 2010;11(2)

9. Ducel, G., Fabry, J., \& Nicolle, L. (2002). Prevention of hospital acquired infections: a practical guide. Prevention of hospital acquired infections: a practical guide(Ed. 2).

10. Shinde MB, Mohite VR. A study to assess knowledge, attitude and practices of five moments of hand hygiene among nursing staff and students at a tertiary care hospital at Karad. Int J Sci Res. 2014;3(2):311-21.

11. Sarani H, Balouchi A, Masinaeinezhad N, Ebrahimitabs E. Knowledge, attitude and practice of nurses about standard precautions for hospitalacquired infection in teaching hospitals affiliated to Zabol University of Medical Sciences (2014). Glob J Health Sci. 2016;8(3):193.

12. Abdulraheem I, Amodu M, Saka M, Bolarinwa O, Uthman M. Knowledge, awareness and compliance with standard precautions among health workers in north eastearn Nigeria. J Community Med Health Edu. 2012;2(3): $1-5$.

13. Alwutaib A, Abdulghafour Y, Alfadhli A, Makboul G, El-Shazly M. Knowledge and attitude of the physicians and nurses regarding blood borne infections in primary health care, Kuwait. Greener J Med Sci. 2012;2(4):107-14.

14. Amin T, Al Wehedy A. Healthcare providers' knowledge of standard precautions at the primary healthcare level in Saudi Arabia. Healthcare Infect. 2009;14(2):65-72.

15. Shamaa E, Talaat E. Developing a control action plan for infection prevention at the endoscopy unit. Int J Acad Res. 2010;2(4):218-27.

16. Fashafsheh I, Ayed A, Eqtait F, Harazneh L. Knowledge and practice of nursing staff towards infection control measures in the Palestinian hospitals. J Educ Pract. 2015;6(4):79-90

17. Kaushal G, Doke P, Shah A, Verma V. An analysis of knowledge, attitude and practices regarding standard precautions of infection control and impact of knowledge and attitude of ICU nurses on self-reported practices of infection control. Int J Res Found Hosp Healthcare Admin. 2015;2:79-85.

18. Johnson O, Asuzu M, Adebiyi A. Knowledge and practice of universal precautions among professionals in public and private health facilities in Uyo, Southern Nigeria-a comparative study. Ibom Med. 2013;5(1):9-19.

19. Reda AA, Fisseha S, Mengistie B, Vandeweerd J-M. Standard precautions: occupational exposure and behavior of health care workers in Ethiopia. PLoS One. 2010:5(12):e14420.

20. El-Sayed M, Gomaa M, Abdel-Aziz M. Nurses' knowledge and practice for prevention of infection in burn unit at a university hospital: suggested nursing guidelines. J Nurs Health Sci. 2015;4(4):62-9.

21. Ebied, E. M. a. E. Impact of a blood-borne diseases prevention program on compliance with infection control standard precautions among nurses in family health centers. Egypt: Elfayoum Governorate; 2011.

22. Isara A, Ofili A. Knowledge and practice of standard precautions among health care workers in the Federal Medical Centre, Asaba, Delta State, Nigeria. Niger Postgrad Med J. 2010;17(3):204-9.

23. Vaz K, McGrowder D, Alexander-Lindo R, Gordon L, Brown P, Irving R. Knowledge, awareness and compliance with universal precautions among health care workers at the University Hospital of the West Indies, Jamaica. Int J Occup Environ Med. 2010;1(4):171-81.

24. Labrague LJ, Rosales RA, Tizon MM. Knowledge and compliance of standard precautions among student nurses. Int J Adv Nurs Stud. 2012;1(2):84-97.

25. Eskander HG, Morsy WY, Elfeky HA. Intensive care nurses' knowledge \& practices regarding infection control standard precautions at a selected Egyptian cancer hospital. Int J Adv Nurs Stud. 2013;1(2):84-97.

26. Taneja J, BibhaBati M, Aradhana B, Poonam L, Vinita D, Archana T. Evaluation of knowledge and practice amongst nursing staff toward infection control measures in a tertiary care hospital in India. Can J Infect Control. 2008:24(2):104-7.

27. Teshager, F. A., Engeda, E. H., \& Worku, W. Z. . Knowledge, practice, and associated factors towards prevention of surgical site infection among nurses working in Amhara regional state referral hospitals, Northwest Ethiopia. Surg Res Pract. 2015:2015. 